\title{
Work-Family Conflict and Job Withdrawal Intentions: The Moderating Effect of Cultural Differences
}

\author{
Peng Wang and John J. Lawler \\ University of Illinois at Urbana-Champaign
}

Fred O. Walumbwa

University of Nebraska-Lincoln

\section{Kan Shi}

Chinese Academy of Sciences

This study examined the interactive effects of individual cultural orientation with work-family conflict on employees' job withdrawal intentions. Using a sample of 394 employees from the banking sector in the United States and China, the authors found that work interfering with family (WIF) was more positively related to job withdrawal intentions among individuals scoring high on idiocentrism. It is interesting to note that the authors (unexpectedly) found that family interfering with work (FIW) was more positively related to job withdrawal intentions for those scoring high on allocentrism or low on idiocentrism. Implications and directions for future research are discussed.

KEY WORDS: work-family conflict; allocentrism; idiocentrism; job withdrawal intentions

As profound changes in family structures and concomitant shifts in job demands increase, women have become increasingly active in the labor force. The dual-earner or single-female-earner family increasingly substitutes for a more traditional single-male family earner. Moreover, men are becoming more active in the family domain (Pleck, 1985), just as women are increasing their participation in the labor force. With these shifts, the

Peng Wang and John J. Lawler, Institute of Labor and Industrial Relations, University of Illinois at Urbana-Champaign; Fred O. Walumbwa, Department of Management, University of Nebraska_Lincoln; Kan Shi, Institute of Psychology, Chinese Academy of Sciences, Beijing, China.

Correspondence concerning this article should be addressed to Peng Wang, who is now at the Department of Management and Marketing, Jackson State University, Jackson, MS 39217. E-mail: pengwang@uiuc.edu 
demand for a better balance between work and home life has greatly increased. Imbalance in the relationship between work and family can be a source of stress resulting in adverse effects on an individual's work attitudes and well-being (e.g., Bacharach, Bamberger, \& Conley, 1991; Frone, Russell, \& Cooper, 1992), as well as to organizations in terms of diminished employee effectiveness.

Greenhaus and Beutell (1985) defined work-family conflict as a form of interrole conflict in which the role pressures from the work and family domains are mutually incompatible in some aspects. Gutek, Searle, and Klepa (1991) further distinguished between two dimensions of workfamily conflict: work interfering with family (WIF) and family interfering with work (FIW). WIF occurs when work pressures interfere with the quality of family life, whereas FIW occurs when family pressures interfere with responsibilities at work.

Employee withdrawal behaviors have been the subject of much research in the organizational sciences for decades (e.g., Griffeth, Hom, \& Gaertner, 2000; Harrison \& Martocchio, 1998; Hom \& Griffeth, 1995; Mitchell, Holtom, Lee, \& Erez, 2001). This is because the corresponding costs to the firm regarding employee absence and turnover can be very significant. Although many companies now recognize the importance of addressing family-work conflict issues, there has been practically no attention to an examination of the interactive effects of work-family conflict and individual cultural orientation in predicting employee withdrawal behaviors. The purpose of this study was to examine the moderating effects of individual cultural orientation in the relationship between work-family conflict and job withdrawal behaviors using data collected from Chinese and U.S. banking sectors. Job withdrawal behaviors refer to sets of behaviors that individuals enact to avoid the dissatisfying work situations, including turnover intentions and desire to retire or resign (Hanisch \& Hulin, 1990).

Studies have consistently supported the positive relationship between WIF and employees' job withdrawal, such as turnover intentions or behaviors (Anderson, Coffey, \& Byerly, 2002; Grandey \& Cropanzano, 1999; Greenhaus, Parasuraman, \& Collins, 2001). Most of these studies, however, have been conducted in North America, where there is a strong individualistic culture. It is relatively unclear as to what the relationship between WIF and withdrawal behaviors would be like in a more collectivistic culture. Although the link between culture and behavior is not as direct, there is emerging consensus among cross-cultural researchers that culture influences people's thinking, emotions, and actions (Earley, 1993; Hofstede, 1997; Schwartz, 1992; Triandis, 1995). Such influence, of course, may differ from society to society depending on whether it is collectivistic or individualistic (Hofstede, 2001). Similarly, it is also possible that people's reactions toward family-work conflict may vary as a function of culture. 
Collectivism refers to societies in which the self is viewed as highly interdependent with others; that is, from birth onward, people are integrated into strong, cohesive in-groups. Individualism characterizes a society in which the self is viewed as largely autonomous and independent from the group (Hofstede, 1997; Triandis, 1995). Collectivists are more concerned with the success of their in-group, and group is the unit of analysis. Individualists are more concerned with personal success and making decisions independently of the in-group, with the individual as the unit of analysis (Markus \& Kitayama, 1991).

Although the constructs of collectivism and individualism have been used by social scientists since at least Durkheim's time, Hofstede (1980) is credited with having introduced the concepts to the study of organizations and with having conceptualized individualism and collectivism as one bipolar dimension of national culture. More recently, researchers (e.g., Robert \& Wasti, 2002; Schwartz, 1994; Triandis, 1995) have argued that individualism and collectivism are independent and can coexist within individuals across national cultures, suggesting a need to examine these constructs as personality attributes. To measure these constructs as individual-level differences, researchers have used the terms allocentrism and idiocentrism (Triandis, 1995). Allocentrism is defined as the individual's tendency to "give ... primary [attention] to the interests, goals, and values shared with other members of a given collective unit" (Parsons \& Shils, 1951, pp. 80-81). Idiocentrism refers to the individual's tendency to "give primary [attention] to his personal or private interests without considering their bearing on collective interest" (Parsons \& Shils, 1951, pp. 80-81).

Our study considered the relationship between job withdrawal intentions and work-family conflict as moderated by culture-related dispositional differences (i.e., idiocentrism and allocentrism) at the individuallevel analysis. We also compared this relationship between China, a highly collectivistic culture, and the United States, a highly individualistic culture. We hypothesized that work-family conflict was related to withdrawal intentions differently between China and the United States and among people who have various cultural dispositional characteristics. More specific research hypotheses were developed, accordingly, as discussed below.

\section{RESEARCH HYPOTHESES}

\section{Work-Family Conflict and Job Withdrawal Intentions}

The work domain is regarded as the root cause of WIF (Frone et al., 1992). Employees experiencing high levels of WIF are more likely to with- 
draw or leave their jobs to reduce or eliminate such conflict directly. Greenhaus et al. (2001) found that increased WIF was related to turnover intentions and behaviors. Netemeyer, Boles, and McMurrian (1996) reported significant and positive correlations between WIF and intentions to leave the organization in samples of primary and high school teachers, small business owners, and salespersons. Grandey and Cropanzano's (1999) data indicated that WIF increased intentions to leave in a sample of 326 university professors. Jones and Butler (1980), using a sample of military personnel, observed that WIF was inversely related to intention to reenlist in the Navy. Taken as a whole, these studies suggest the following.

Hypothesis 1: WIF is positively associated with job withdrawal intentions.

FIW occurs when family pressure limits one's performance at work. Because the determinants of FIW reside within the family domain, individuals who experience extensive FIW do not necessarily leave their jobs. Even if they switch jobs, FIW may still remain, because the source of FIW - the family situation - does not always change with a change in job. This position has received support empirically. Frone (2003) suggested that WIF, but not FIW, predicts voluntary turnover. Greenhaus et al. (2001) found a significant and positive relationship between WIF and turnover but not between FIW and turnover. Anderson et al. (2002) analyzed data from the 1997 National Study of the Changing Workforce and reported that WIF was related to turnover intentions, whereas FIW was related to absenteeism. On the basis of these findings, we did not expect to observe any significant relationship between FIW and job withdrawal intentions.

\section{China-United States Comparison of the Relationship Between WIF and Job Withdrawal Intentions}

China and the United States are identified as two prototypes of collectivistic and individualistic societies, respectively (Bond \& Hwang, 1995; Hofstede, 1997). We speculated that there would be a generally stronger relationship between WIF and job withdrawal intentions in the United States than in China. First, in collectivistic cultures, employees are expected to be more concerned with the long-term relationship with their organizations, and organizations should reciprocate for employees' loyalty (Triandis \& Suh, 2002; Verma, 1992). Rewards from the organizations can range from social welfare benefits to allocating broader responsibilities for 
in-group members (Hofstede, 2001). Thus, given their cultural orientations, employees from collectivist cultures can be expected to sacrifice selfinterest and serve in-group goals when self and in-group goals are not compatible. Individualistic cultures represent the exact opposite. Such cultures are based on the rational analysis of the costs and benefits of maintaining a relationship. People are expected to show a more calculative involvement and establish short-term relationships with their organizations (Triandis \& Suh, 2002). According to Hofstede (2001), personal and family time or goals are seen to be more valuable in individualistic societies. In such cultures, people are expected to work when self-goals and organizational goals coincide. When work events endanger their desirable family and personal time, it would be socially acceptable to sacrifice employers' interest by leaving the job.

Second, in individualistic cultures, people are taught to think that the "I" unit is paramount. Achievement motivation is individually oriented, and it is expected that behavior will be regulated largely by personal needs (Triandis, 1995) and that careers will serve for self-development separately from family life (Schein, 1985). Conversely, in a collectivistic culture, people most often grow up physically and psychologically in the extended family. Children from birth are expected to be interdependent and regard themselves as part of a "we" unit. People are expected to have total loyalty to their in-group and share resources among in-group members (Hofstede, 2001). For example, a family may collectively cover the educational expenses of a single family member. Once such a person gets a well-paying job, he or she is expected to share the income with other family members. The view supported by Chinese culture is that extra work serves as the individual's self-sacrifice for the family's benefit, while American culture promotes the view that extra work sacrifices family life in the pursuit of one's own career (Yang, Chen, Choi, \& Zhou, 2000). Extra work may be legitimized or even encouraged in collectivistic societies, where the value of financial survival is usually prevalent (Hofstede, 2001), but may be discouraged in individualistic societies, where lifestyle or quality-of-life issues are usually given higher priority (Inglehart, 1990, 1997). Even if financial survival is not an imperative in a collectivist society, achievement by a family member contributes to the overall stature of the family, thus enhancing "face" (especially relevant in Chinese culture). Thus, we expect that collectivist cultural norms will make Chinese individuals less inclined to leave their jobs when faced with WIF and that, for the opposite reasons, Americans in general will react by being more inclined to leave their jobs when faced with WIF.

Hypothesis 2: WIF is more positively associated with job withdrawal intentions in the United States than in China. 


\section{The Moderating Effect of Allocentrism and Idiocentrism at the Individual-Level Analysis}

National culture (i.e., societal-level individualism-collectivism) is a central tendency related to specific values that leads to social pressures and norms to behave and interpret the world in certain ways. However, individual differences in cultural values (i.e., individual-level allocentrism and idiocentrism) can impact behavior as well. These individual cultural orientations exist in all societies as well as in all individuals (e.g., Triandis, McCusker, \& Hui, 1990; Schaubroeck, Lam, \& Xie, 2000). There is a need to assess how the individual-level allocentrism and idiocentrism contribute to employees' behaviors. We expected that individual cultural orientation can moderate the relationship between WIF and job withdrawal intentions independent of the social norms created by national culture.

Idiocentric individuals define the self as an entity consisting of a single person. Allocentric individuals define the self as an entity extending beyond the individual to include a particular group of others, bounded by the social perimeter of that group (Wagner, 1995). Realo, Koido, Ceulemans, and Allik (2002) suggested that those people scoring high on idiocentrism are more autonomous, whereas those people scoring high on allocentrism are less autonomous. A highly autonomous person relies on his or her independent judgment without reference to other people, thus is likely to view leaving his or her job as purely an individual act. Such people are likely to show a more calculative involvement and establish nonintimate and short-term relationships with their organization (Triandis \& Suh, 2002). That is, whenever they feel their individual goals or lives are endangered by group interests or organizational events, they will easily choose to leave the organization. Conversely, because allocentric individuals are more likely to use in-group norms to shape their behavior than personal attitudes, they are more likely to put more weight on groupshared norms (i.e., extended family, friends, co-workers) when making decisions. If there is inconsistency in opinions between the individual and the in-group, this is likely to affect a decision to leave the job (Triandis \& Suh, 2002; Verma, 1992).

Allocentric individuals see the environment as fixed and themselves as changeable; idiocentric individuals see themselves as stable and the environment as changeable (Chiu, Dweck, Tong, \& Fu, 1997; Chiu \& Hong, 1999; Triandis \& Suh, 2002). This view has received support empirically.

Norenzayan, Choi, and Nisbett (1999) reported that people in East Asia (generally allocentric individuals) see dispositional traits as quite malleable, whereas people in Western countries (generally idiocentric individuals) see them as fixed. Thus, when individuals experience high levels of WIF resulting from demanding work environments, allocentric individuals 
are more likely to change themselves to fit the fixed work environment; idiocentric individuals are more likely to change the malleable work environment by leaving their jobs.

Finally, idiocentric individuals emphasize self-reliance and emotional distance from in-groups (Triandis, Leung, Villareal, \& Clack, 1985; Triandis \& Suh, 2002). When WIF occurs, they are likely to rely on themselves to resolve the conflict instead of seeking help from the outside. In contrast, allocentric individuals value interdependence and sociability. They feel small social distances between self and in-groups, such as friends, family, and work groups (Cross, Bacon, \& Morris, 2000; Iyengar, Lepper, \& Ross, 1999). Even in individualistic cultures, allocentric individuals are more likely to join groups such as communes and unions (Triandis \& Suh, 2002). The more support allocentric individuals obtain, the more they are able to cope with WIF and feel less stress. As a result, they may be less likely to leave their jobs because they are more able to manage the problem of WIF with other in-group members' support.

Thus, we propose the following hypotheses.

Hypothesis 3: Allocentrism moderates the association between WIF and job withdrawal intentions such that WIF is more strongly related to job withdrawal intentions for those scoring low on allocentrism.

Hypothesis 4: Idiocentrism moderates the association between WIF and job withdrawal intentions such that WIF is more strongly related to job withdrawal intentions for those scoring high on idiocentrism.

\section{METHOD}

\section{Sample and Procedures}

Our sample consisted of bank employees in both China and the United States. The banking sector was selected because, in addition to controlling for industry type error, this sector tends to contain employees who are more educated and mainly in the middle class (compared with, e.g., factory workers). Furthermore, there is generally a relatively large proportion of women employed in the banking sector. Thus, banking represents an area of employment in which work-family conflict issues are more apt to be experienced, particularly in the case of a developing economy such as China.

In each bank, a human resource manager or a chief executive officer (CEO) was contacted to obtain permission for their employees to participate in the study. The manager or CEO then randomly selected employees 
in each branch for participation in the study. Managers were asked to assist in the distribution of questionnaires; however, the completed questionnaires were collected by one of the research team members in accordance with procedures approved by our university's institutional review board. Participants were also advised as to the confidential nature of the information they were providing and their rights.

In China, the questionnaire was administered on-site in seven different banks by one of our research team members. The response rate was $96 \%$. Because the questionnaire was developed in English, the questionnaire was translated into Chinese, following the conventional method of backtranslation described by Brislin (1980). A bilingual speaker performed the initial translation from English into Chinese. After this, the questionnaire was given to another bilingual translator, who then back-translated it into English.

In the United States, the questionnaire was sent to potential participants in five selected Midwestern banks through their internal mailing system, with a response rate of $93 \%$. Respondents were provided with confidential envelopes to seal their responses. As part of our promise to these companies for participation, we reported only aggregated data results to each organization. Again, we took appropriate steps and assured employees that all information would be anonymous and remain confidential.

The total number of respondents obtained was 230 in China and 243 in the United States. Only participants who lived with at least one other family member at home (i.e., spouse, child, or an elder or disabled relative) were included in the study. The final data consisted of 214 usable cases from China and 180 from the United States. Table 1 presents the demographic characteristics of the sample for this study. The average age was 33 years $(S D=6.13)$ for China and 42 years $(S D=12.29)$ for the United States. Women composed $64 \%$ of the total sample (United States $=74 \%$; China $=56 \%$ ). Participants in both countries were relatively well educated, with more than $93 \%$ having attended college. The average organization tenure was 8 years $(S D=5.1)$ for China and 9.6 years $(S D=9.3)$ for the United States.

\section{Measures \\ Work-Family Conflict}

Work-family conflict was assessed using scales developed by Netemeyer et al. (1996). Five items measured WIF (coefficient $\alpha=.88$; .77 for China and .93 for the United States) and FIW (coefficient $\alpha=.84 ; .80$ for 
Table 1. Demographic Characteristics of the Study

\begin{tabular}{lccc}
\hline \multicolumn{1}{c}{ Variable } & China & United States & Combined \\
\hline Total respondents $^{\mathrm{b}}$ & $214(51.7)$ & $180(48.3)$ & $394(100)$ \\
Age $^{\mathrm{a}}$ & $32.88(6.13)$ & $42.23(12.29)$ & $37.19(10.56)$ \\
Organization tenure $^{\mathrm{a}}$ & $7.98(5.05)$ & $9.61(9.27)$ & $8.74(7.34)$ \\
Gender $^{\mathrm{b}}$ & & & \\
Male & $94(43.9)$ & $47(26.1)$ & $141(35.8)$ \\
Female & $119(55.6)$ & $133(73.9)$ & $252(64.1)$ \\
Not reported & $1(0.5)$ & $0(0)$ & $1(0.3)$ \\
Marital status & & & \\
Never married & $24(11.2)$ & $0(0)$ & $24(6.1)$ \\
Married or living together & $183(85.5)$ & $156(86.7)$ & $339(86)$ \\
Separated or divorced & $6(2.8)$ & $20(11.1)$ & $26(6.6)$ \\
Widowed & $0(0)$ & $4(2.2)$ & $4(1)$ \\
Not reported & $1(0.5)$ & $0(0)$ & $1(0.3)$ \\
Education & & & \\
Some high school & $1(0.5)$ & $25(13.9)$ & $26(6.7)$ \\
Some college or diploma & $74(34.6)$ & $98(54.4)$ & $172(43.7)$ \\
University degree & $122(57)$ & $48(26.7)$ & $170(43.1)$ \\
Postgraduate degree(s) & $9(4.2)$ & $9(5)$ & $18(4.6)$ \\
Not reported & $8(3.7)$ & $0(0)$ & $8(2)$ \\
Position & & & \\
Managerial & $26(12.1)$ & $33(18.3)$ & $59(15)$ \\
Professional & $47(22)$ & $61(33.9)$ & $108(27.4)$ \\
Administrative & $14(6.5)$ & $30(16.7)$ & $44(11.2)$ \\
Technical & $19(8.9)$ & $4(2.2)$ & $23(5.8)$ \\
Clerical & $47(22)$ & $27(15)$ & $74(18.8)$ \\
Other positions & $33(15.4)$ & $22(12.2)$ & $55(14)$ \\
Employment status & & & \\
Full-time employee & $196(91.6)$ & $170(94.4)$ & $366(92.9)$ \\
Part-time employee & $3(1.4)$ & $10(5.6)$ & $13(3.3)$ \\
Not reported & $15(7)$ & $0(0)$ & $15(3.8)$ \\
\hline
\end{tabular}

${ }^{\text {a }}$ Reported as means (standard deviations are in parentheses). ${ }^{\mathrm{b}}$ Percentages are in parentheses.

China and .87 for the United States), respectively, ranging from strongly disagree (1) to strongly agree (5). Sample items included, "The demands of my work interfere with my home and family life" (WIF), and "Familyrelated strain interferes with my ability to perform job-related duties" (FIW).

\section{Job Withdrawal Intentions}

A six-item scale developed by Hanisch and Hulin $(1990,1991)$ was used to measure the extent to which respondents have thought of quitting (coefficient $\alpha=.73 ; .79$ for China and .69 for the United States). A sample item included, "How often do you think about quitting your job?" Responses were made on a 5-point scale, with 1 representing never and 5 representing constantly. 


\section{Allocentrism and Idiocentrism}

Allocentrism (coefficient $\alpha=.66 ; .70$ for China and .62 for the United States) and idiocentrism (coefficient $\alpha=.61 ; .63$ for China and .69 for the United States) were measured by 22 items adopted from the INDCOL scale (Singelis, Triandis, Bhawuk, \& Gelfand, 1995; Triandis, 1995). These items address the extent to which respondents agree or disagree that they exhibited allocentric and idiocentric attributes. Although the coefficient alphas for allocentrism and idiocentrism scales are somewhat low, they are consistent with past studies that have used similar items (e.g., Lawler, Probst, Robert, \& Martocchio, 2000; Robert \& Wasti, 2002) and thus can be said to be acceptable and reasonable for scales measuring broad constructs such as cultural differences (Singelis et al., 1995). Sample items included, "I usually sacrifice my self-interest for the benefit of my group" (allocentrism), and "My personal identity independent from others is very important to me" (idiocentrism). Responses ranged from $1=$ strongly disagree to $5=$ strongly agree.

\section{Control Variables}

Age, gender, education, organization tenure, and job level were used as control variables in this study. As career stage indicators, age and tenure have been found to influence job turnover intentions or behaviors (Hellman, 1997; Lynn, Cao, \& Horn, 1996; Manlove \& Guzell, 1997; Riordan, Griffith, \& Weatherly, 2003). This body of research suggests that employees who are older or have stayed with an organization for a long time are likely to become emotionally involved with the organization, resulting in less intention to quit. Education was found to be positively correlated with turnover intentions in work by Cotton and Tuttle (1986) and Steel and Rentsch (1995). Prior research (e.g., Cotton \& Tuttle, 1986; Greenhaus, Collins, Singh, \& Parasuraman, 1997; Steel \& Rentsch, 1995) has shown that women are more likely to leave their jobs than men for family reasons. Finally, there is evidence to suggest that people in higher job levels may perceive their work and workplace more positively, thus are unlikely to leave their jobs (Carlopio \& Gardner, 1995; Sawyer, 1989).

\section{RESULTS}

\section{Preliminary Analyses}

One of the pressing issues in cross-cultural research is establishing construct comparability in different cultures (Little, 1997). To address this 
issue, we used a combination of mean and covariance structures (MACS; Byrne, 2001) and simultaneous factor analysis in several populations (SIFASP; Jöreskog, 1971). Both techniques were performed using AMOS maximum likelihood estimation (Arbuckle \& Wothke, 1999; Byrne, 2001). Following the work of Fitzgerald, Drasgow, Hulin, Gelfand, and Magley (1997), we formed multi-item indicators for each of the constructs. This procedure was chosen because of its ability to generate more stable parameter estimates. To do this, progressively restricted models are fit to multisample data to test the assumption that factor loadings are equivalent across samples (Little, 1997). In the unrestricted model, each indicator was allowed to load only on its factor, but the factor loadings and covariances were allowed to vary between China and the United States. In the restricted model, factor loadings were restricted to be invariant between the two countries, but the covariances were free to vary. The chi square/ degrees of freedom ratio was less than 2.3, the goodness-of-fit index was .93 , the comparative fit index was .92 , and the root-mean-square error of approximation was .06 in both models, indicating a reasonable fit to the data. All the estimated factor loadings were significant and reasonably close to 1.00 , suggesting that the indicators measured the latent traits well. Finally, because our models are nested, their differences in chi square can be compared with their differences in degrees of freedom (Robert, Probst, Martocchio, Drasgow, \& Lawler, 2000). The ratio was 10.82/7 $=.95, p=$ .15 , indicating that the factor loadings were approximately equivalent across the two samples. Table 2 presents means, standard deviations, and correlations of major variables in the study.

\section{Tests of Hypotheses}

Tests of hypotheses were performed using hierarchical regression. However, before performing our analysis, all main-effect variables were

Table 2. Means, Standard Deviations, and Correlations

\begin{tabular}{|c|c|c|c|c|c|c|c|c|c|}
\hline \multirow[b]{2}{*}{ Variable } & \multicolumn{2}{|c|}{ China } & \multicolumn{2}{|c|}{ United States } & \multirow[b]{2}{*}{1} & \multirow[b]{2}{*}{2} & \multirow[b]{2}{*}{3} & \multirow[b]{2}{*}{4} & \multirow[b]{2}{*}{5} \\
\hline & $M$ & $S D$ & $M$ & $S D$ & & & & & \\
\hline \multirow{2}{*}{$\begin{array}{l}\text { 1. Work interfering } \\
\text { with family } \\
\text { 2. Family interfering } \\
\text { with work }\end{array}$} & 2.92 & .75 & 2.36 & 1.02 & - & $.52 * *$ & .04 & .11 & $.21 * *$ \\
\hline & 1.95 & .65 & & .68 & & - & & .08 & 5 \\
\hline \multirow{3}{*}{$\begin{array}{l}\text { 3. Allocentrism } \\
\text { 4. Idiocentrism } \\
\text { 5. Job withdrawal } \\
\text { intentions }\end{array}$} & 3.70 & .39 & 3.80 & .36 & -.01 & $-.35^{* *}$ & - & $.31 * *$ & .07 \\
\hline & 3.43 & .38 & 3.42 & .42 & $.13^{*}$ & -.12 & $.37 * *$ & - & -.02 \\
\hline & 2.48 & .68 & 2.2 & .62 & .05 & $.17 *$ & -.13 & $.22 * *$ & - \\
\hline
\end{tabular}

Note. $\quad n=214$, China; $n=180$, United States. Correlations for China are below the diagonal, and those for the United States are above the diagonal.

$* p<.05 . \quad * * p<.01$. 
mean-centered. This was done to reduce possible multicollinearity and to facilitate model estimation when main effects and interactive effects were both present (Aiken \& West, 1991).

Hypothesis 1 predicts that WIF is positively associated with job withdrawal intentions. Hypothesis 2 predicts the differences in the relationship between WIF and job withdrawal intentions between two country samples. To test these hypotheses, we performed separate regression analyses for the Chinese and United States samples. We first entered control variables into the equation, followed by two explanatory variables: WIF and FIW. Table 3 summarizes the results of the regression analyses. To test if significant differences existed between the two countries, we performed $t$ tests between raw regression coefficients (Cohen, Cohen, West, \& Aiken, 2003). WIF was significantly and positively related to job withdrawal intentions in the United States sample $(\beta=.20, p<.05)$ but not in the Chinese sample $(\beta=.02, p>.1)$. Hypothesis 1 was thus supported only in the United States sample. A one-tailed $t$ test for the two independent samples showed that the relationship between WIF and job withdrawal intentions was not more positive in the United States than in China at the .05 level, $t(392)=1.45, p>.05, n=392$. Hypothesis 2 was not supported. It is interesting to note that the results also showed that FIW was positively and significantly associated with job withdrawal intentions in the Chinese sample $(\beta=.18, p<.01)$. However, when we performed $t$ tests, no significant differences in the relation between FIW and job withdrawal intentions were detected between China and the United States, $t(392)=1.24, p>.1, n=392$.

Tests for the moderating effects of allocentrism and idiocentrism were performed using moderated multiple regression (Stone \& Hollenbeck, 1984). We first entered all controls into the equation. Next, we entered WIF and FIW, followed by allocentrism and idiocentrism in the third step. In the fourth step, we entered two-way interactions. Table 3 summarizes the results of the regression analyses. As can be seen, idiocentrism moderated the relation between WIF and job withdrawal intentions $(\beta=.14, p$ $<.05)$. Allocentrism, however, failed to moderate the relation between WIF and job withdrawal intentions $(\beta=-.08, p>.1)$. Consequently, Hypothesis 4 was supported, but Hypothesis 3 was not. Unexpectedly, idiocentrism $(\beta=-.23, p<.001)$ moderated the relation between FIW and job withdrawal intentions. Overall, the inclusion of the interaction terms into the equation explained a significant amount of additional variance in job withdrawal intentions $\left(\Delta R^{2}=.04, p<.001\right)$.

To further explore these moderating effects, we plotted regression lines for those scoring one standard deviation above and one standard deviation below the mean on allocentrism and idiocentrism (Aiken \& West, 1991). Figure 1 represents the interaction between idiocentrism and 
Table 3. Effects of Work Interfering With Family, Family Interfering With Work, Allocentrism, Idiocentrism, and Job Withdrawal Intentions-Standardized Regression Coefficients

\begin{tabular}{|c|c|c|c|}
\hline \multirow[b]{2}{*}{ Independent variable } & \multicolumn{3}{|c|}{ Job withdrawal intentions } \\
\hline & Chinese sample & $\begin{array}{l}\text { American } \\
\text { sample }\end{array}$ & Combined \\
\hline \multicolumn{4}{|l|}{ Step 1} \\
\hline Country_China & & & $.16 * *$ \\
\hline Age & $-.17 *$ & -.14 & $-.14 *$ \\
\hline Gender-Male & .05 & -.17 & -.06 \\
\hline Tenure & -.04 & -.02 & -.07 \\
\hline \multicolumn{4}{|l|}{ Education } \\
\hline Some college or diploma & $-.44 *$ & -.04 & $-.19 *$ \\
\hline University degree & -.18 & .12 & -.00 \\
\hline Postgraduate degree & .15 & -.02 & .06 \\
\hline \multicolumn{4}{|l|}{ Job level } \\
\hline Manager & .14 & .07 & .11 \\
\hline Professional & $.18^{*}$ & .09 & .09 \\
\hline Administrative & .02 & .05 & .04 \\
\hline Technical & -.01 & -.09 & -.06 \\
\hline Clerical & .06 & .06 & .03 \\
\hline$\Delta R^{2}$ & .24 & .08 & .15 \\
\hline$F$ & $5.21 * * *$ & 1.22 & $5.10 * * *$ \\
\hline \multicolumn{4}{|l|}{ Step 2} \\
\hline Work interfering with family & .02 & $.20 *$ & .06 \\
\hline Family interfering with work & $.18 * *$ & .05 & $.14 * *$ \\
\hline$\Delta R^{2}$ & .03 & .04 & .03 \\
\hline$F$ & $5.10 * * *$ & 1.64 & $5.26 * * *$ \\
\hline \multicolumn{4}{|l|}{ Step 3} \\
\hline Allocentrism & & & -.05 \\
\hline Idiocentrism & & & .07 \\
\hline$\Delta R^{2}$ & & & .01 \\
\hline$F$ & & & $4.73 * * *$ \\
\hline \multicolumn{4}{|l|}{ Step 4} \\
\hline Work Interfering With Family $\times$ Allocentrism & & & -.08 \\
\hline Work Interfering With Family $\times$ Idiocentrism & & & $.14 *$ \\
\hline Family Interfering With Work $\times$ Allocentrism & & & .11 \\
\hline Family Interfering With Work $\times$ Idiocentrism & & & $-.23 * * *$ \\
\hline$\Delta R^{2}$ & & & .04 \\
\hline$F$ & & & $4.91 * * *$ \\
\hline
\end{tabular}

Note. Work interfering with family, family interfering with work, allocentrism, and idiocentrism were mean centered.

$* p<.05 . \quad * * p<.01 . \quad * * * p<.001$.

WIF. The graph shows that the effect of WIF on job withdrawal intentions was more positive as the level of idiocentrism increased, providing support for Hypothesis 4. Figure 2 depicts the interaction between idiocentrism and FIW and between allocentrism and FIW. The results suggest that the effect of FIW on job withdrawal intentions was more positive as the level of idiocentrism decreased or as the level of allocentrism increased. 


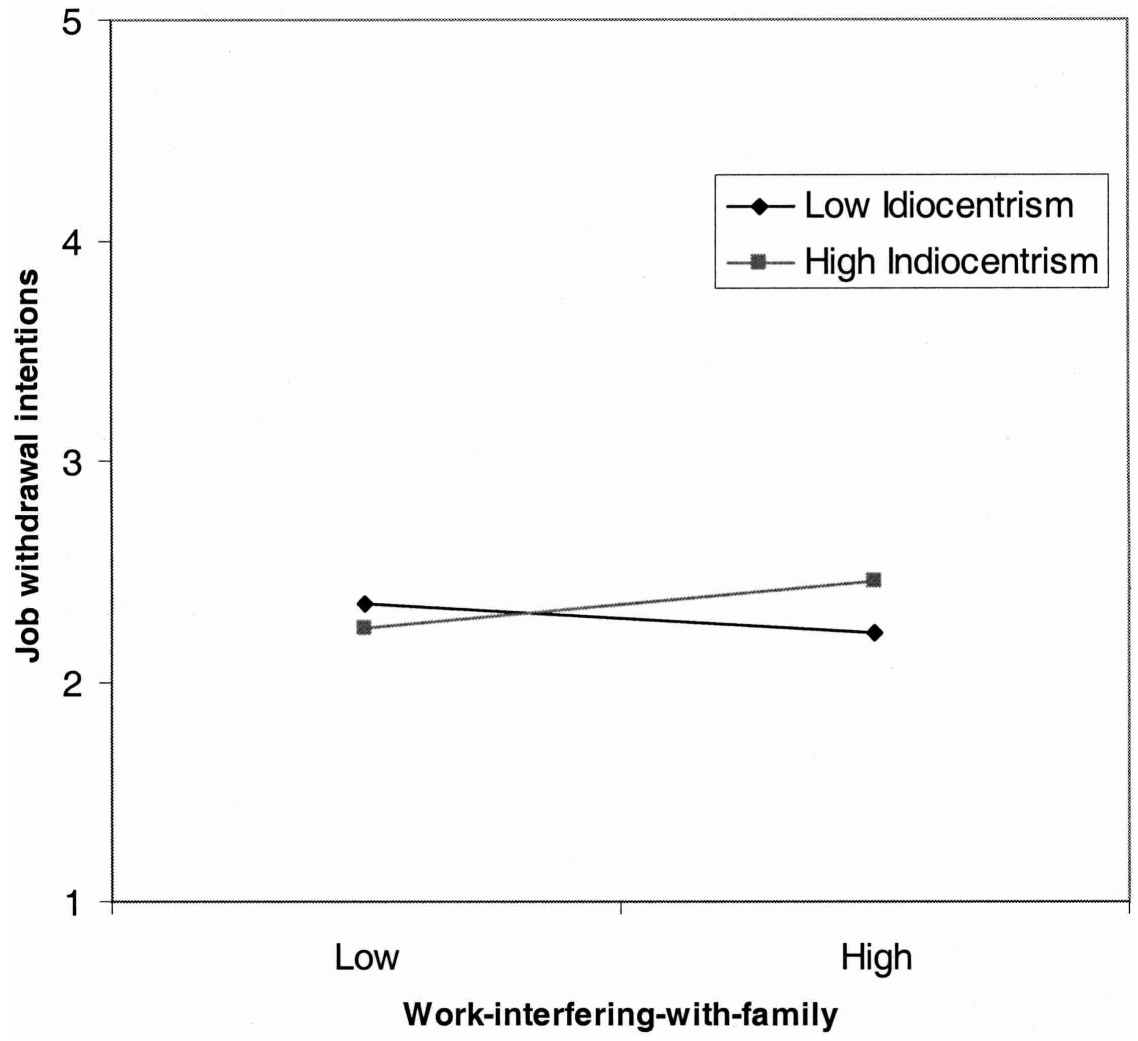

Figure 1. The interactive effect of work-interfering-with-family and idiocentrism in predicting job withdrawal intentions.

\section{DISCUSSION}

This study extends our knowledge of work-family conflict by incorporating the role of cultural differences into the process. The results from our U.S. sample were consistent with the argument that WIF predicts higher levels of turnover intentions and behaviors (i.e., Anderson et al., 2002; Frone, 2003; Greenhaus, Parasuraman, \& Collins, 2001). However, our findings further revealed no significant difference in the effect of WIF on job withdrawal intentions between the United States and China. Instead, WIF was more positively related to job withdrawal intentions among people scoring high on idiocentrism (regardless of national cultural norms). Unexpectedly, we found out that FIW was significantly and positively associated with job withdrawal intentions in China. Our individual-level analysis suggested that FIW was more positively related to job withdrawal 


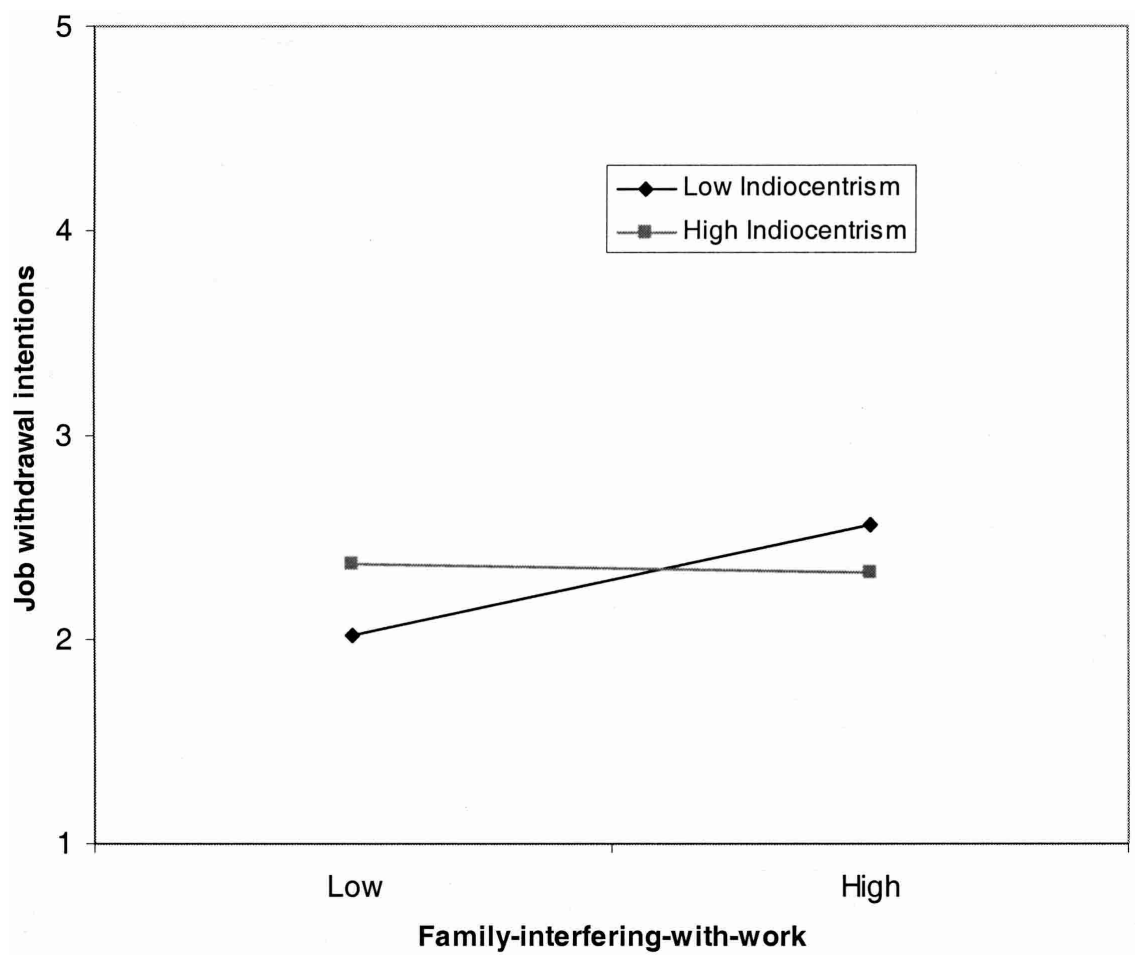

Figure 2. The interactive effect of family-interfering-with-work and idiocentrism in predicting job withdrawal intentions.

intentions among those scoring low on idiocentrism. These findings are interesting because they sharply contrast with results from earlier studies (e.g., Anderson et al., 2002; Frone, 2003; Greenhaus et al., 2001), which reported no association between FIW and turnover intentions.

The lack of a differential effect of WIF on job withdrawal intentions between the United States and China may reflect the transition currently taking place in contemporary Chinese society. The shift to a profit-driven market economy in China has inevitably conditioned self-focused values and behaviors. The ideology of individualism has been introduced through increased cultural, commercial, and personnel exchange between China and Western countries. Individualism is becoming popular, especially with the younger generation in China. Consequently, dissimilarities along the individualism-collectivism cultural dimension may become decreasingly prominent between China and the United States. This may be a possible reason why we did not observe a significant difference in the relationship between WIF and job withdrawal intention. 
The results of our study also demonstrate how individual differences, namely allocentrism and idiocentrism, might influence the relationship between WIF and job withdrawal intentions. The findings suggest that the strength of the relationship between WIF and withdrawal is contingent on individual variations in cultural values. Individual cultural attributes may influence the appraisal and reaction to the conflict. When studying the effect of WIF on individuals' behaviors, researchers should also consider the interactive effect of situational and personal variables.

It is interesting to note that we unexpectedly found that FIW was significantly and positively related to job withdrawal in China, a predominantly collectivist society. The effect of FIW on job withdrawal intentions was stronger among people scoring low on idiocentrism or high on allocentrism. These findings are different from those in the existing literature. For example, Frone (2003) argued that FIW is not likely to result in employees' quitting their job because the source of interference does come from the family domain. Consequently, leaving a job would not be anticipated to reduce an individual's level of stress. Though this argument has received consistent empirical support in North American studies (see Anderson et al., 2002; Greenhaus et al., 2001), it has received less empirical attention across cultures. Our results suggest that this argument may need modification when considering collectivistic cultures. Perhaps, because of their loyalty to family, people low in idiocentrism or high in allocentrism are likely to be motivated to fulfill their excessive family responsibilities, even if it interferes with their work performance. Moreover, because of their social-orientation scheme, they may feel obligated to continue work in order to assure the material well-being of the family. The dilemma is thus created and may intensify their stress levels, which may consequently make them leave their current jobs for a less demanding or more flexible work environment.

\section{Implications}

This study has theoretical and practical implications for future research. Theoretically, the present study extends previous research by incorporating cultural influences into the analysis of work-family conflict and job withdrawal intentions. Our results suggest that individual cultural differences moderate the effects of work-family conflict on job withdrawal intentions. We are aware of no study that has examined the interactive effects of individual cultural orientation with work-family conflict to explain employees' job withdrawal behaviors. This is an important area for future research. 
Practically, our results suggest that the relationships between workfamily conflict and job withdrawal intentions might be a function of individual differences in culturally influenced values. These findings have practical implications for managerial practices in multinational corporations. For instance, it may be beneficial for multinational companies to include cultural components when designing and delivering training programs in order to have the greatest impact. The findings also suggest that it might be helpful for managers of multinational organizations to think carefully about issues of work-family conflict. Clearly, results from this study suggest that efforts that are highly effective in addressing work-family conflict in an individualist culture will not automatically transfer to the collectivist cultural context.

\section{Limitations and Conclusions}

As with all research, our study is bound by certain limitations that warrant further attention. First, we measured job withdrawal intentions rather than actual behavior. Although past studies (e.g., Hanisch \& Hulin, 1990, 1991) suggest that behavioral intentions or perceptions are an ideal substitute for actual behaviors when the ability to measure actual behaviors is constrained, this limits generalization of our findings. Future studies should attempt to measure actual behaviors, not intentions as surrogates, as in the present study.

Second, the use of cross-sectional data precludes definitive assertions regarding causality and directionality. Although job withdrawal intentions are theoretically more likely to be the consequence rather than predictors of work-family conflict, longitudinal research design is necessary to reveal the true directions of these relationships. However, such studies must take into consideration the optimal time lag. Otherwise, longitudinal data might provide biased parameter estimates worse than those obtained from crosssectional data.

Third, because data for this study were collected by means of selfreport, this raises the possibility of the common-method variance problem. To address this potential problem, we performed Harman's (1967) singlefactor statistical procedure. Results indicated the presence of five factors, suggesting that common-method variance was not a serious problem in the present study, although this strategy does not completely rule out the common method bias problem. It is also important to point out that although the likelihood of common-method bias cannot be denied, commonmethod variance cannot explain why certain variables exhibit expected relationships while others do not (Jex \& Bliese, 1999). Moreover, commonmethod variance problems would tend to dampen or obscure, rather than 
accentuate, interaction effects. The fact that our study provides support for several specified interaction effects thus also is suggestive of limiting problems in this area.

A final limitation is the fact that the present sample focused on a single industry - the banking sector. Though this allowed us to match samples between the United States and China, our sample pool was nevertheless restrictive. In future studies, it would be useful to replicate these findings in a more occupationally diverse sample.

Despite these limitations, the present study makes an important contribution to our understanding about the effect of work-family conflict in diverse cultural contexts. More specifically, our research contributes to literature by developing a better understanding of how work-family conflict affects individuals' job withdrawal intentions. To our knowledge, this is the first study to systematically examine the relations between workfamily conflict and job withdrawal intentions taking a cross-cultural perspective. Therefore, we hope that the results of the current study will stimulate further investigation in this area.

\section{REFERENCES}

Aiken, L. S., \& West, S. G. (1991). Multiple regression testing and interpreting interactions. Newbury Park, CA: Sage.

Anderson, S. E., Coffey, B. S., \& Byerly, R. (2002). Formal organizational initiatives and informal workplace practices: Links to work-family conflict and job-related outcomes. Journal of Management, 28, 6, 787-810.

Arbuckle, J. L., \& Wothke, W. (1999). AMOS 4.0 user's guide. Chicago: Smallwaters.

Bacharach, S. B., Bamberger, P., \& Conley, S. (1991). Work-home conflict among nurses and engineers: Mediating the impact of role stress on burnout and satisfaction at work. Journal of Organizational Behavior, 12(1), 39-53.

Bond, M. H., \& Hwang, K. K. (1995). The social psychology of Chinese people. In M. H. Bond (Ed.), The psychology of the Chinese people (pp. 213-266). Hong Kong: Oxford University Press.

Brislin, R. W. (1980). Translation and content analysis of oral and written materials. In H. C. Triandis \& J. W. Berry (Eds.), Handbook of cross-cultural psychology (Vol. 2, pp. 389-444). Boston, MA: Allyn \& Bacon.

Byrne, B. M. (2001). Structural equation modeling with AMOS: Basic concepts, applications, and programming. Mahwah, NJ: Erlbaum.

Carlopio, J., \& Gardner, D. (1995). Perceptions of work and workplace: Mediators of the relationship between job level and employee reactions. Journal of Occupational \& Organizational Psychology, 68(4), 321-326.

Chiu, C., Dweck, C. S., Tong, J. Y., \& Fu, J. H. (1997). Implicit theories and conceptions of morality. Journal of Personality and Social Psychology, 73, 923-940.

Chiu, C., \& Hong, Y. (1999). Social identification in a political transition: The role of implicit beliefs. International Journal of Intercultural Relations, 23, 297-318.

Cohen, J., Cohen, P., West, S. G., \& Aiken, L. S. (2003). Applied multiple regression/ correlation analysis for behavioral sciences (3rd ed.). Mahwah, NJ: Erlbaum.

Cotton, J. L., \& Tuttle, J. M. (1986). Employee turnover: A meta-analysis and review with implications for research. Academy of Management Review, 11(1), 55-70. 
Cross, S. E., Bacon, P., \& Morris, M. (2000). The relational-interdependent self-construal and relationships. Journal of Personality and Social Psychology, 78, 791-798.

Earley, P. C. (1993). East meets West meets Mideast: Further explorations of collectivistic and individualistic work groups. Academy of Management Journal, 36(2), 319-348.

Fitzgerald, L. F., Drasgow, F., Hulin, C. L., Gelfand, M., \& Magley, V. J. (1997). Antecedents and consequences of sexual harassment in organizations: A test of an integrated model. Journal of Applied Psychology, 82, 578-589.

Frone, M. R. (2003). Work-family balance. In J. C. Quick \& L. E. Tetrick (Eds.), Handbook of occupational health psychology (pp. 143-162). Washington, DC: American Psychological Association.

Frone, M. R., Russell, M., \& Cooper, M. L. (1992). Antecedents and outcomes of work-family conflict: Testing a model of the work-family interface. Journal of Applied Psychology, $77,1,65-78$

Grandey, A. A., \& Cropanzano, R. C. (1999). The conservation of resources model applied to work-family conflict and strain. Journal of Vocational Behavior, 54, 350-370.

Greenhaus, J. H., \& Beutell, N. J. (1985). Sources and conflict between work and family roles. Academy of Management Review, 10(1), 76-88.

Greenhaus, J. H., Collins, K. M., Singh, R., \& Parasuraman, S. (1997). Work and family influences on departure from public accounting. Journal of Vocational Behavior, 50(2), 249-270.

Greenhaus, J. H., Parasuraman, S., \& Collins, K. M. (2001). Career involvement and family involvement as moderators of relationships between work-family conflict and withdrawal from a profession. Journal of Occupational Health Psychology, 6(2), 91-100.

Griffeth, R. W., Hom, P. W., \& Gaertner, S. (2000). A meta-analysis of antecedents and correlates of employee turnover: Updates, moderators, and research implications for the millennium. Journal of Management, 26, 463-488.

Gutek, B. A., Searle, S., \& Klepa, L. (1991). Rational versus gender role explanations for work-family conflict. Journal of Applied Psychology, 76, 560-568.

Hanisch, K. A., \& Hulin, C. L. (1990). Job attitudes and organizational withdrawal: An examination of retirement and other voluntary withdrawal behaviors. Journal of Vocational Behavior, 37, 60-78.

Hanisch, K. A., \& Hulin, C. L (1991). General attitudes and organizational withdrawal: An evaluation of a causal model. Journal of Vocational Behavior, 39, 110-128.

Harman, H. H. (1967). Modern factor analysis. Chicago, IL: University of Chicago Press.

Harrison, D. A., \& Martocchio, J. J. (1998). Time for absenteeism: A 20-year review of origins, offshoots, and outcomes. Journal of Management, 24, 305-350.

Hellman, C. M. (1997). Job satisfaction and intent to leave. Journal of Social Psychology, 137, 677-689.

Hofstede, G. (1980). Culture's consequences: International differences in work-related values. Beverly Hills, CA: Sage.

Hofstede, G. (1997). Cultures and organizations: Software of the mind-Intercultural cooperation and its impact for survival. New York: McGraw-Hill.

Hofstede, G. (2001). Culture's consequences: Comparing values, behaviors, institutions and organizations across nations. Thousand Oaks, CA: Sage.

Hom, P. W., \& Griffeth, R. W. (1995). Employee turnover. Cincinnati, OH: South-Western. Inglehart, R. (1990). Culture shift in advanced industrial society. Princeton, NJ: Princeton University Press.

Inglehart, R. (1997). Modernization and postmodernization: Cultural, economic, and political change in 43 societies. Princeton, NJ: Princeton University Press.

Iyengar, S. S., Lepper, M. R., \& Ross, L. (1999). Independence from whom? Interdependence with whom? Cultural perspectives on ingroups versus outgroups. In D. A. Prentice \& D. T. Miller (Eds.), Cultural divides: Understanding and overcoming group conflict (pp. 273-301). New York: Russell Sage Foundation.

Jex, S. M., \& Bliese, P. D. (1999). Efficacy beliefs as a moderator of the impact of work-related stressors: A multilevel study. Journal of Applied Psychology, 84, 349-361.

Jones, A. P., \& Butler, M. C. (1980). A role transition approach to the stresses of organizationally induced family role disruption. Journal of Marriage and the Family, 42, 367-376. 
Jöreskog, K. G. (1971). Simultaneous factor analysis in several populations. Psychometrika, 36, 409-426.

Lawler, J. J., Probst, T. R., Robert, C., \& Martocchio, J. J. (2000). Empowerment, continuous improvement and the influence of culture. Unpublished manuscript, University of Illinois, Urbana.

Little, T. (1997). Mean and covariance structures (MACS) analyses of cross-cultural data: Practical and theoretical issues. Multivariate Behavioral Research, 32, 53-76.

Lynn, S. A., Cao, L. T., \& Horn, B. C. (1996). The influence of career stage on the work attitudes of male and female accounting professionals. Journal of Organizational Behavior, 17(2), 135-149.

Manlove, E. E., \& Guzell, J. R. (1997). Intention to leave, anticipated reasons for leaving, and 12 month turnover of child care center staff. Early Childhood Research Quarterly, 12(2), $145-167$.

Markus, H. R., \& Kitayama, S. (1991). Culture and self: Implications for cognition, emotion and motivation. Psychological Review, 98, 224-253.

Mitchell, T. R., Holtom, B. C., Lee, T., \& Erez, M. (2001). Why people stay: Using job embeddedness to predict voluntary turnover. Academy of Management Journal, 44, $1101-1121$.

Netemeyer, R. G., Boles, J. S., \& McMurrian, R. (1996). Development and validation of work-family conflict and family-work conflict scales. Journal of Applied Psychology, 81, 400-410.

Norenzayan, A., Choi, I., \& Nisbett, R. E. (1999). Eastern and Western perceptions of causality for social behavior: Lay theories about personalities and situations. In D. A. Prentice \& D. T. Miller (Eds.), Cultural divides: Understanding and overcoming group conflict (pp. 239-272). New York: Russell Sage Foundation

Parsons, T., \& Shils, E. A. (Eds.). (1951). Toward a general theory of action. Cambridge, MA: Harvard University Press.

Pleck, J. H. (1985). Working wives/working husbands. Beverly Hills, CA: Sage.

Realo, A., Koido, K., Ceulemans, E., \& Allik, J. (2002). Three components of individualism. European Journal of Personality, 16(3), 163-184.

Riordan, C. M., Griffith, R. W., \& Weatherly, E. W. (2003). Age and work-related outcomes: The moderating effects of status characteristics. Journal of Applied Social Psychology, 33(1), 37-57.

Robert, C., Probst, T. M., Martocchio, J. J., Drasgow, F., \& Lawler, J. J. (2000). Empowerment and continuous improvement in the United States, Mexico, Poland, and India: Predicting fit on the basis of dimensions of power distance and individualism. Journal of Applied Psychology, 85, 643-658.

Robert, C., \& Wasti, S. A. (2002). Organizational individualism and collectivism: Theoretical development and an empirical test of a measure. Journal of Management, 28, 544-566.

Sawyer, J. E. (1989). Measuring attitudes across job levels: When are scale scores truly comparable? Organizational Behavior and Human Decision Processes, 42(3), 324-342.

Schaubroeck, J., Lam, S. K., \& Xie, J. L. (2000). Collective efficacy versus self-efficacy in coping responses to stressors and control: A cross-cultural study. Journal of Applied Psychology, 85, 512-525.

Schein, E. H. (1985). Organizational culture and leadership. San Francisco, CA: Jossey-Bass.

Schwartz, S. A. (1992). Universals in the content and structure of values: Theoretical advances and empirical tests in 20 countries. In M. Zanna (Ed.), Advances in experimental social psychology (Vol. 25, pp. 1-66). New York: Academic Press.

Schwartz, S. A. (1994). Beyond individualism and collectivism: New cultural dimensions of values. In U. Kim, H. C. Triandis, C. Kagitcibasi, S.-C. Choi, \& G. Yoon (Eds.), Individualism and collectivism: Theory, method and applications (pp. 85-122). Newbury Park, CA: Sage.

Singelis, T. M., Triandis, H. C., Bhawuk, D. P. S., \& Gelfand, M. J. (1995). Horizontal and vertical dimensions of individualism and collectivism: A theoretical and measurement refinement. Cross-Cultural Research, 29, 240-275.

Steel, R. P., \& Rentsch, J. R. (1995). Influence of cumulation strategies on the long-range prediction of absenteeism. Academy of Management Journal, 38, 1616-1634. 
Stone, F. E., \& Hollenbeck, J. R. (1984). Some issues associated with the use of moderated regression. Organizational Behavior and Human Performance, 34, 195-213.

Triandis, H. C. (1995). The self and social behavior in differing cultural contexts. In N. R. Goldberger \& J. B. Veroff (Eds.), The culture and psychology reader (pp. 326-365). New York: New York University Press.

Triandis, H. C., Leung, K., Villareal, M. J., \& Clack, F. L. (1985). Allocentric versus idiocentric tendencies: Convergent and discriminant validation. Journal of Research in Personality, 19(4), 395-415.

Triandis, H. C., McCusker, C., \& Hui, C. H. (1990). Multimethod probes of individualism and collectivism. Journal of Personality and Social Psychology, 59, 1006-1020.

Triandis, H. C., \& Suh, E. M. (2002). Cultural influences on personality. Annual Review of Psychology, 53(1), 133-160.

Verma, J. (1992). Allocentrism and relational orientation. In S. Iwawaki, Y. Kashinma, \& K. Leung (Eds.), Innovations in cross-cultural psychology (pp. 152-163). Lisse, the Netherlands: Swets \& Zeitlinger.

Wagner, J. A. (1995). Studies of individualism-collectivism: Effects of cooperation in groups. Academy of Management Journal, 38(1), 152-172.

Yang, N. N., Chen, C., Choi, J., \& Zhou, Y. M. (2000). Sources of work-family conflict: A Sino-U.S. comparison of the effects of work and family demands. Academy of Management Journal, 43(1), 113-123. 